\title{
Covid-19, moda y políticas públicas: los peligros del confinamiento de animales salvajes en la industria peletera
}

\author{
Cristian Apiolaza Acevedo \\ Director Legal de Fundación Vegetarianos Hoy, Chile \\ María Ignacia Uribe Rojas \\ Fundadora y Directora General de Fundación Vegetarianos Hoy, Chile
}

Recepción: Septiembre 2020

Aceptación: Noviembre 2020

Cita recomendada. APIOLAZA ACEVEDO, C., URIBE ROJAS, M.I., Covid-19, moda y políticas públicas: los peligros del confinamiento de animales salvajes en la industria peletera, dA. Derecho Animal (Forum of Animal Law Studies) 11/4 (2020). - DOI https://doi.org/10.5565/rev/da.526

\section{Resumen}

En el contexto actual de la crisis sanitaria mundial que ha generado la pandemia del Coronavirus, se hace necesario poner atención sobre otras fuentes posibles de transmisión de zoonosis, como lo es la industria peletera. En ella, se crían de forma intensiva animales salvajes -como visones y zorros, entre otros- con el objetivo de utilizar su piel para confeccionar prendas de alta costura, aun cotizadas en algunos centros de la moda internacional. Aunque algunos países ya han comenzado hace años a legislar para poner fin a las granjas peleteras, como es el caso de Holanda, el reciente brote de Covid-19 en una de las últimas instalaciones que quedan abiertas en este mismo país, ha levantado desde otro frente una nueva alerta acerca de cómo enfrentar la industria de las pieles a nivel mundial. A la luz de esta evidencia, y teniendo presente el gasto fiscal sin precedentes de la mayoría de los países en un contexto de paralización comercial y la caída del PIB a nivel global, se postula, por una parte, una revisión de las disposiciones legales transitorias sobre el cierre de la industria peletera y, por otra parte, la urgente implementación de legislación acorde en aquellos países que hoy no cuentan con normas al respecto, como es el caso de Chile y España.

Palabras clave: moda; pieles animales; pieles sintéticas; peletería; animales salvajes; confinamiento; zoonosis; paralización comercial; gasto fiscal; legislación; normas.

\section{Abstract - Covid-19, fashion and public policy: the dangers of confining wild animals for the fur industry}

In the current context of the global health crisis generated by the Coronavirus pandemic, it becomes necessary to pay attention to other possible sources of zoonosis transmission, such as the fur industry. For this, wild animals are intensively raised - such as mink and foxes, among others - with the aim of using their fur to make haute couture garments, which are still sought-after in some international fashion centres. Although some countries have for years begun to legislate to put an end to fur farms, as is the case in the Netherlands, the recent outbreak of Covid-19 in one of the last facilities that remain open there has raised a new alert from another front about how to confront the fur industry on a worldwide level. In light of this evidence, and bearing in mind the unprecedented public spending of most countries in a context of commercial paralysis and the fall in GDP at the global level, it has proposed there be, on the one hand, a review of the transitory legal provisions for the closure of the fur industry, and, on the other hand, the urgent implementation of appropriate legislation in those countries that do not currently have standards in this regard, such as Chile and Spain.

Keywords: fashion; animal fur; synthetic fur; fur industry; wild animals; confinement; zoonosis; commercial paralysis; public spending; legislation; regulations. 


\section{Introducción}

La aparición de al menos dos casos documentados de contagio por Covid-19 desde animales no humanos a personas sanas en granjas de pieles en Holanda, y los posteriores sacrificios de miles de visones tanto en Holanda como España, no solo han activado las alarmas en cuanto a las cuestiones éticas, sanitarias y económicas propiamente tales de esta crisis, sino que también ha reactivado la discusión en torno al necesario fin de la industria de pieles animales.

Una situación sin duda aberrante para los animales no humanos que fueron y están siendo sacrificados en estas granjas peleteras en Europa, es también la posibilidad real y única de enfrentar a la industria peletera con más y nuevas herramientas y argumentos, exigiendo su desaparición definitiva a propósito del actual contexto.

Por ello, luego de referirnos a la industria de la moda y a los principales hitos que sustentaron la actual tendencia global fur free, analizaremos con detención el caso de Holanda y sus consecuencias a nivel de la Unión Europea, incluyendo el caso particular de España y, aunque en otra zona del planeta, el caso de Chile frente a estos hechos.

Posteriormente, nos referiremos a los factores que resaltan en esta situación, y que terminan siendo necesarios para darle sustento a la idea -y la necesidad- de terminar con la industria peletera. Por ello, en la última parte, nos referiremos a lineamientos básicos a tener en cuenta para establecer propuestas diferenciadas según la realidad propia de cada país, pero siempre compartiendo el mismo objetivo: el fin de la industria peletera.

\section{Moda}

Según el diccionario de la Real Academia Española ${ }^{1}$, entre las distintas acepciones respecto del término moda podemos entenderla como:

1. f. Uso, modo o costumbre que está en boga durante algún tiempo, o en determinado país.

2. f. Gusto colectivo y cambiante en lo relativo a prendas de vestir y complementos.

3. f. Conjunto de la vestimenta y los adornos de moda.

En la práctica, la industria de la moda es una industria de carácter global, y una de las industrias más influyentes y de mayor facturación ${ }^{2}$, cuyo objetivo es ocuparse del arte y el diseño de lo que usamos a diario como vestimenta. La moda es por definición cambiante y, por lo tanto, efímera. Y a pesar de su gran magnitud, no es de primera necesidad.

Teniendo esto claro, también podemos agregar que dentro de la moda existen distintas corrientes y tendencias. Y hoy la tendencia es que las grandes marcas se están alejando del uso de pieles y otros insumos de origen animal, tanto por cuestiones relacionadas al maltrato y sufrimiento de los animales como al impacto medioambiental de la producción de pieles.

Así por ejemplo, durante el año 2018 el reconocido diseñador Michel Kors anunció que dejaría de usar pieles en sus confecciones dado el avance tecnológico y sus consecuencias positivas para la industria de la moda $^{3}$. Ese mismo año, la revista Vogue dijo que ser fur free era el primer paso que deberían tomar aquellas marcas que quieran ser más sustentables ${ }^{4}$, mientras que la revista People anunció el año pasado a la tendencia fur free como el último grito de la moda ${ }^{5}$. También durante el 2019, Kim Kardashian West, un ícono de las fashion influencers, anunció que había pedido confeccionar sus abrigos de piel favoritos ahora en versión fur free $^{6}$, mientras que el famoso modisto Jean Paul Gaultier dejó de usar pieles en sus confecciones luego de haberlas usado durante 30 años ${ }^{7}$.

\footnotetext{
${ }^{1}$ Real Academia Española. Página web: https://dle.rae.es/moda [Última fecha de consulta: 31 de agosto de 2020]

${ }^{2}$ Solo durante el año 2017, la marca Louis Vuitton Moët Hennessy obtuvo ganancias por 48.113 millones de dólares, mientras que la marca Nike obtuvo ganancias por 34.000 millones de dólares, y la marca Inditex (Zara, Pull\&Bear, Massimo Dutti, Bershka, Stradivarius, Oysho y Uterqüe) por 28.619 millones de dólares. Avianca. Página web:

https://www.aviancaenrevista.com/revista/especial-moda-las-cifras-de-la-industria-textil/ [Última fecha de consulta: 13 de agosto de 2020]

${ }^{3}$ La Vanguardia. Página web: https://www.lavanguardia.com/de-moda/moda/20180110/434198166438/michael-kors-jimmy-choopieles-animales-iniciativa-peta-gucci.html [Última fecha de consulta: 13 de agosto de 2020]

${ }_{4}$ Evening Standard. Página web: https://www.standard.co.uk/fashion/luxury-brands-are-ditching-animal-fur-gucci-michael-korsmaison-margiela-versace-a3805921.html [Última fecha de consulta: 13 de agosto de 2020]

${ }^{5}$ People. Página web: https://people.com/style/fur-free-luxury-fashion-brands/ [Última fecha de consulta: 13 de agosto de 2020]

${ }^{6}$ W Magazine. Página web: https://www.wmagazine.com/story/kim-kardashian-faux-fur-coats/ [Última fecha de consulta: 13 de agosto de 2020]

7 'Just-Style. Página web: https://www.just-style.com/news/jean-paul-gaultier-to-go-fur-free_id134992.aspx [Última fecha de
} 
Siguiendo esta misma tendencia, al día de hoy más de 300 casas de moda y firmas se han sumado a la moda fur free, destacando entre muchas otras, Versace, Lacoste, Gucci, Hugo Boss, Armani y Zara ${ }^{8}$.

\section{La vida en las granjas y el impacto medioambiental}

Según Nimon y Broom (1999), los visones son confinados en jaulas con una superficie de suelo de aproximadamente 90 × $30 \mathrm{cms}$. $(0,27 \mathrm{~m} 2)$ con una altura de aproximada de $30-40 \mathrm{cms}$. A cada una de estas jaulas se une a través de un orificio circular un dormitorio o nido de una superficie aproximada de $25 \mathrm{cms}$. $(0,06 \mathrm{~m} 2)$. Mientras que el dormitorio esta hecho generalmente de madera con techo de malla metálica, las jaulas están hechas por completo de malla cuadrada de acero galvanizado con el objeto de que las heces de los visones caigan al suelo. Este tipo de construcción no permite que los visones estén resguardados de los climas fríos y calurosos, generando problemas de bienestar animal en este sentido.

Por una parte, los visones tienen acceso al agua mediante sistemas automatizados y se les alimenta una o dos veces al día con alimento que se deja en el techo de sus jaulas. Por otra parte, estas jaulas se ordenan en filas, unidas unas con otras y separadas por mallas metálicas u otros materiales, dentro de cobertizos en donde se colocan en filas en paralelo en la cantidad que el espacio total lo permita.

Al respecto, estos autores señalan que "es evidente que las condiciones de alojamiento del visón en las granjas difieren notablemente de las del visón en la naturaleza en términos de la crianza de sus crías, la proximidad de otros visones y la oportunidades para nadar y bucear, deambular, usar diferentes guaridas y participar en actividad física. Sin duda, el ambiente olfativo y las condiciones lumínicas de las granjas también difieren mucho de las condiciones en la naturaleza"".

El confinamiento en este tipo de espacios, en general no enriquecidos, y que no permiten la realización de comportamientos naturales, conlleva a la aparición en los visones de movimientos estereotipados, es decir, patrones de movimientos repetitivos e invariables que no tienen una función particular. Más bien, son característicos de espacios o medioambientes restrictivos en donde se mantienen confinados animales con un alto grado de frustración y sufrimiento. Sumado a esto último, hay que agregar la forma en que se les da muerte, señalando que "cuando tienen solamente unos meses de edad son gaseados o electrocutados, o se les rompe el cuello. Los hay que son despellejados mientras siguen con vida y plenamente conscientes $(\ldots)^{10 "}$.

En cuanto al impacto medioambiental de la producción de piel de visones, un estudio realizado ya el año 2011 por la consultora independiente CE Delft cuantificó el impacto medioambiental de la cadena de producción "desde el pienso hasta la piel" (ciclo vital de los visones) en los siguientes términos ${ }^{11}$.

- Producir 1 kilogramo de piel de visón requiere de más de 11 visones.

- Un visón consume 50 kilogramos de alimento en su vida productiva, por lo que requieren 563 kilos de alimento para producir 1 kilo de piel de visón. Además, el tipo de alimentación de los visones carne, pollo, pescado y trigo, entre otros- cubre 14 de los 18 factores de impacto ambiental estudiados en este informe.

- En comparación con los textiles, las pieles de visón tienen un mayor impacto por kilogramo en 17 de los 18 factores de impacto ambiental estudiados en este informe, incluyendo el cambio climático, eutrofización y emisiones tóxicas.

- También en comparación con los textiles, el estiércol de los visones produce una mayor cantidad de emisiones de $\mathrm{N} 2 \mathrm{O}$ (óxido nitroso) y NH3 (amoniaco), las que contribuyen principalmente a la acidificación y la formación de partículas.

- Se puede concluir que en términos de impacto del cambio climático, 1 kilo de piel de visón es cinco veces mayor que el impacto de 1 kilo de lana.

Incluso más allá de la cuestión del impacto negativo al medioambiente, en cuanto al tema principal, es evidente que este tipo de espacios de confinamiento, como lo son también los espacios de los animales confinados por la industria de productos de origen animal -ya sean establecimientos cerrados o mercados abiertos-, son espacios inadecuados desde el punto de vista sanitario debido a que no permiten mantener un alto grado de limpieza y desinfección. Es decir, son reservorios de bacterias y virus.

consulta: 13 de agosto de 2020]

${ }^{8}$ Fur Free Retailer. Página web: https://furfreeretailer.com/ [Última fecha de consulta: 13 de agosto de 2020]

${ }^{9}$ NIMON, J. Y BROOM, M., The welfare of farmed mink (Mustela vison) in relation to housing and management: a review, en Animal Welfare, 8 (1999) 209.

${ }^{10}$ HORTA, O. Un paso adelante en defensa de los animales (Madrid 2017) 93.

${ }^{11}$ BIJLEVELD, M., KORTELAND, M., SEVENSTER, M., The environmental impact of mink fur production (Paises Bajos, 2011)

6-7.

190 Derecho Animal. Forum of Animal Law Studies, vol. 11/4 


\section{Animales infectados por coronavirus: el caso de Holanda}

Teniendo presente la tendencia mundial de la moda a transformarse en fur free, ¿por qué hablar hoy, en este año 2020, sobre comercio e industria de pieles de animales?

Si hay algo que caracterizará al año 2020 es la pandemia global del coronavirus. Al mismo tiempo que millones de seres humanos se han contagiado y muerto debido al covid-19, también se han registrado varios casos de animales no humanos contagiados por humanos. A propósito de animales que conviven con nosotros, perros, gatos y hasta hámsteres han sido infectados por sus tutores ${ }^{12}$; mientras que también se han dado a conocer casos de animales salvajes en cautiverio contagiados por sus cuidadores, como por ejemplo algunos monos y un tigre del Zoológico del Bronx, en Nueva York ${ }^{13}$.

Hay que destacar, por una parte, que todos estos animales contrajeron coronavirus debido al contacto que mantuvieron con seres humanos que resultaron positivos al covid19 y que, por otra parte, en ninguno de estos casos se ha registrado alguna persona sana que haya sido contagiada por estos animales. Esto hasta que se registraron los primeros casos en la industria de pieles.

Se trata de los únicos casos registrados y comprobados en que el virus se transmitió, primero, de seres humanos a animales no humanos, y luego desde animales no humanos a seres humanos - esto cuando a la fecha de la redacción de este documento, aún no se ha logrado establecer con certeza cuál es el origen del virus en China. La situación relatada sucedió en las granjas peleteras de visones en Holanda, tercer productor a nivel mundial de pieles de visón, en donde se comprobó que el virus mutó en animales contagiados y estos infectaron posteriormente al menos a dos personas ${ }^{14}$.

Los primeros brotes en granjas peleteras de visones en Holanda fueron reportados entre el 23 y 25 de abril del 2020 en establecimientos con 12.000 y 7.500 visones, respectivamente ${ }^{15}$. En ambos casos, los animales fueron infectados por trabajadores que tenían covid-19, para luego esparcirse rápidamente por las instalaciones entre los propios visones, esto a pesar de que estos animales se mantienen confinados en jaulas pequeñas y separadas. La sospecha del contagio masivo comenzó cuando más animales de lo normal empezaron a morir, mostrando dificultades para respirar. Posterior a esto, más casos de visones contagiados con coronavirus se han reportado en al menos 17 de las más de 100 granjas peleteras de visones en este país, ante lo cual las autoridades del Gobierno holandés han decidido sacrificar a miles de visones mediante gas ${ }^{16}$.

En el caso de Holanda, el 18 de diciembre de 2012 se aprobó una ley que prohíbe de forma definitiva el funcionamiento de las 170 granjas peleteras de visones que existen en dicho país ${ }^{17}$. Aunque este proyecto de ley que comenzó a discutirse en el año 1999 fijaba inicialmente el cierre definitivo de todas las granjas de visones para el 2018, esta idea no logro la mayoría en el parlamento holandés. El principal argumento que se utilizó en contra de esta prohibición en aquel año fueron los problemas económicos a los que se dejaba expuestos a los dueños de estas granjas peleteras. Por esta razón, se modificó el proyecto en cuanto establecer una compensación individual a cada granjero, pero al mismo tiempo fijando el año 2024 como el año para el cierre definitivo de estas granjas en todo el país.

Con el contagio masivo de coronavirus entre los visones cautivos en estas granjas -sumándose al menos 2 granjas en Dinamarca, el principal productor de este tipo de pieles del mundo- y la posibilidad real de contagio hacía seres humanos, ya no se trata tan solo de un tema ético de trato hacia los animales, sino que se ha transformado en un tema de salud pública ${ }^{18}$. Por ello, el viernes 28 de agosto de 2020 , el parlamento holandés finalmente decidió el cierre de manera permanente de todas las granjas peleteras de visones para marzo del año 2021, adelantando en la práctica la fecha de cierre que el proyecto de ley había establecido para el año 2024. Esto aprovechando el cierre momentáneo de las granjas peleteras en Holanda debido al coronavirus, y ante la posibilidad cierta de la compensación económica para sus dueños. Esta medida le costará al gobierno holandés 180 millones de euros: 40 millones en la matanza preventiva de visones y 140

\footnotetext{
12 La Tercera. Página web: https://www.latercera.com/que-pasa/noticia/estudios-los-confirman-perros-y-gatos-pueden-contagiarsede-coronavirus-pero-no-tienes-de-que-preocuparte/R37YQWXLBRG3HHBRSMQPSHISIY/ [Última fecha de consulta: 13 de agosto de 2020]

${ }^{13}$ BBC. Página web: https://www.bbc.com/mundo/noticias-52181584 [Última fecha de consulta: 13 de agosto de 2020]

14 La Vanguardia. Página web: https://www.lavanguardia.com/natural/20200525/481386452450/holanda-coronavirus-visonescontagio-humanos.html [Última fecha de consulta: 14 de agosto de 2020]

15 Science. Página web: https://www.sciencemag.org/news/2020/06/coronavirus-rips-through-dutch-mink-farms-triggering-cullsprevent-human-infections [Última fecha de consulta: 14 de agosto de 2020]

${ }^{16}$ CNN Chile. Página web: https://www.cnnchile.com/mundo/holanda-sacrificar-visones-covid-19_20200706/ [Última fecha de consulta: 14 de agosto de 2020]

17 Igualdad Animal. Página web: https://igualdadanimal.org/noticia/2012/12/18/holanda-prohibe-finalmente-las-granjas-de-visones/ [Última fecha de consulta: 18 de agosto de 2020]

18 ABC. Página web: https://www.abc.es/sociedad/abci-parlamento-holandes-pide-cerrar-granjas-vison-este-tras-contagioscoronavirus-202006240139_noticia.html?ref=https:\%2F\%2Fwww.google.com\%2F [Última fecha de consulta: 15 de agosto de 2020]
} 
millones en indemnizaciones para la industria ${ }^{19}$.

El caso de Dinamarca, primer productor de pieles de visón a nivel mundial, es aún más grave. De junio a noviembre de 2020, se han detectado 214 personas infectadas con cepas mutadas de covid19 provenientes de la industria peletera de visones. $\mathrm{Y}$ tras detectar una nueva e inquietante mutación del covid19 que se transmitió a al menos 12 personas, las autoridades de dicho país han tomado la determinación de sacrificar a 17 millones de visones, la cual califican como una medida necesaria y adecuada ${ }^{20}$. La gravedad de la situación en Dinamarca es que estas nuevas mutaciones ponen en jaque la eficacia de las vacunas contra el coronavirus apuntando al riesgo de que estas no funcionen como se tenía previsto ${ }^{21}$.

La situación de Holanda y Dinamarca también ha conllevado la crítica general a la crianza de animales salvajes como visones, zorros, conejos y chinchillas, entre otros, en la industria peletera a nivel mundial ${ }^{22}$, ya que representa un riesgo inaceptable y totalmente innecesario tanto para la salud humana como para la salud y bienestar de decena de millones de animales. Se entiende que ahora, más allá de las cuestiones éticas propias de los derechos animales, este tipo de establecimientos son la base para el brote y la mutación de enfermedades infecciones para los humanos y otros animales -como también lo han sido en el caso del MERS, SARS y H1N1-, estableciendo con claridad que los productos de origen animal no cuentan ya con la característica de ser seguros desde el punto de vista sanitario.

Y aunque la anterior es la postura mayoritaria, China -segundo productor de pieles de visón a nivel mundial- ya ha anunciado a través de su Ministro de Agricultura, ante la presión internacional para terminar con la cría de animales salvajes en espacios reducidos, que realizaran una reclasificación de los visones, zorros, y otras especies de animales salvajes ahora como animales "domésticos," y así continuar con su explotación comercial. Cabe mencionar que de acuerdo a un reporte de la Chinese Academy of Engineering del 2016, un 75\% de las ventas de animales salvajes en China se da por la industria de las pieles, y que en China se crían y sacrifican a más de 50 millones de animales en granjas de pieles cada año ${ }^{23}$.

\section{La situación en Chile}

Teniendo presente que la situación global respecto del contagio del coronavirus y el comercio de pieles de origen animal está asociado no solo a una cuestión ética de derechos animales, sino que también a una urgente revisión de los aspectos de seguridad sanitaria y transmisión de enfermedades contagiosas, cabe preguntarse cuál es la situación y que pueden hacer otros países al respecto.

En Chile, por una parte, no existe una ley que prohíba el funcionamiento de granjas peleteras de animales salvajes, y tampoco existe una ley específica que regule esta materia en particular. Lo único que existe en el país es una ley general de protección animal, la Ley $\mathrm{N}^{\circ} 20.380$ sobre Protección Animal, del 03 de octubre de 2009. La única referencia de esta ley al tema de las pieles de animales tiene relación con que esta norma señala que será el decreto respectivo el que fijará los procedimientos técnicos apropiados para el sacrificio o beneficio de animales que provean pieles (artículo 11 inciso segundo).

Al respecto, el Decreto $\mathrm{N}^{\circ} 28$ sobre Protección de los animales que provean de carne, pieles, plumas y otros productos al momento del beneficio en establecimientos industriales, señala precisamente en su ámbito de aplicación que las disposiciones de esta norma determinarán solamente los procedimientos técnicos para el beneficio y sacrificio de animales silvestres que provean pieles, entre otros animales. Mientras que el Decreto $\mathrm{N}^{\circ} 29$ sobre Protección de los animales durante su producción industrial, su comercialización y en otros recintos de mantención de animales, se establecen normas de protección para animales silvestres que provean pieles, entre otros animales, durante las etapas en que se mantengan en confinamiento. Y aunque este último reglamento menciona temas generales aplicables a los animales salvajes en granjas peleteras, como que ciertos manejos de los animales están prohibidos, como golpearlos causando dolor y sufrimiento innecesario (artículo 6); lineamientos para el suministro de alimento y agua (artículo 8 y siguientes); características de las construcciones y equipamientos de los establecimientos, así como de las condiciones ambientales de las instalaciones (artículos 11 y 12); y planes de contingencia para enfrentar emergencias

\footnotetext{
${ }^{19}$ El Mundo. Página web: https://www.elmundo.es/economia/2020/08/28/5f48c914fdddff78928b45bf.html [Última fecha de consulta: 15 de noviembre de 2020]

20 DW. Página web: https://www.dw.com/es/dinamarca-defiende-sacrifico-de-millones-de-visones/a-55525617 [Última fecha de consulta: 15 de noviembre de 2020]

21 Infobae. Página web: https://www.infobae.com/salud/ciencia/2020/11/14/la-mutacion-de-covid-19-procedente-de-visones-seriamas-mortal-y-podria-alterar-el-desarrollo-de-las-vacunas-en-proceso/ [Última fecha de consulta: 15 de noviembre de 2020]

${ }^{22}$ Independent. Página web: https://www.independent.co.uk/environment/coronavirus-fur-trade-mink-farms-netherlandsa9500061.html [Última fecha de consulta: 15 de agosto de 2020]

${ }^{23}$ Independent. Página web: https:/www.independent.co.uk/news/world/asia/coronavirus-fur-farm-china-mink-raccoon-fox-wildanimal-a9506976.html [Última fecha de consulta: 14 de agosto de 2020]
} 
(artículo 14), entre otros, ninguno de ellos es de aplicación específica para los recintos de granjas peleteras.

Por otra parte, en cuanto a la información disponible que se tiene de la industria y del comercio de pieles de animales silvestres en Chile, lo cierto es que no existe información pública al respecto. Por ello, el pasado 15 de junio de 2020 realizamos una solicitud de información mediante el procedimiento establecido en la Ley $\mathrm{N}^{\circ} 20.285$ sobre Acceso a la Información Pública, solicitud que se realizó al Servicio Agrícola y Ganadero (SAG), unidad dependiente del Ministerio de Agricultura, que cumple el rol fiscalizador sobre esta materia según la Ley $\mathrm{N}^{\circ} 20.380$ y sus reglamentos ya mencionados. Dicha solicitud consistió en lo siguiente:

1. Listado actualizado de todas aquellas instalaciones, cualquiera sea su dimensión y/o tamaño, que se dediquen única y exclusivamente a la reproducción, crianza y sacrificio de animales de cualquier tipo en el contexto del comercio de pieles / industria peletera en todo el territorio nacional;

2. Listado actualizado que indique número total o promedio de animales mantenidos por instalación, así como también el tipo de animal indicando especie / raza, según lo establecido en el numeral anterior de esta solicitud;

3. Listado actualizado en que se indiquen de forma precisa todas aquellas normas específicas que tengan aplicación en cualquiera de las etapas del comercio de pieles / industria peletera en todo el territorio nacional.

La respuesta de esta institución pública, como veremos, es demostrativa de los problemas asociados que existen respecto del acceso a la información sobre esta temática específica, pero también del ineficiente rol fiscalizador de este ente. En este sentido, nos llaman la atención los siguientes aspectos en dicha respuesta:

1. En relación a la solicitud del número total o promedio de animales mantenidos en las instalaciones donde se produzcan y procesen pieles, el SAG sostiene que esta información podría afectar los derechos de carácter comercial y económico de los productores de esos establecimientos, sin explicar en qué serían afectados.

2. De todas maneras, señala que existen 193 productores que declaran el rubro piel, agregando que, dado el número de involucrados, esto significaría que sólo el proceso de notificación implicaría destinar un tiempo excesivo por parte de los funcionarios públicos, sin considerar el tiempo que debería destinarse al análisis de la información generada por esas respuestas. Señalan que esto podría distraer a los funcionarios públicos del cumplimiento de otras funciones públicas (sic);

3. Señala también que no posee listados de establecimientos que se dediquen única y exclusivamente al rubro de pieles, sino un registro pecuario con un objetivo sanitario, donde el rubro piel es sólo un elemento más que caracteriza a los establecimientos y productores;

4. Finalmente, puntualiza que el SAG no tiene atribuciones ni responsabilidades en regular este comercio, aun cuando su rol fiscalizador está establecido por ley (artículos 5 inciso primero y 11 de la Ley $\mathrm{N}^{\circ} 20.380$ ).

De todas maneras, teniendo presente que el SAG se negó a entregar cifras totales o promedios de la cantidad de animales que podrían estar en estas instalaciones, podemos sacar algunas conclusiones a propósito de la información parcial de los 193 productores del rubro piel. Del total de estos productores, 175 (90,7\%) se dedican a la crianza de bovinos, ovinos, mulares, caprinos, conejos, asnales, llamas, alpacas, caballares, porcinos, aves, cérvidos, ratites, jabalíes, equinos y camélidos, entre otros, por sus pieles. Mientras que tan sólo 18 productores $(9,3 \%)$ aparecen como productores de otros tipos de pieles, en donde cabrían los animales salvajes.

\section{Unión Europea}

El 11 de diciembre del 2007, la Unión Europea aprobó el Reglamento (CE) № 1523/2007, el cual establece la prohibición de comercialización e importación a la Comunidad Europea, o exportación desde esta, de pieles de perro y de gato y de productos que las contengan (artículo 3), estableciendo como únicas excepciones cuando se realice para fines educativos o de taxidermia (artículo 4). Como es evidente, se trata de una norma solo aplicable a este tipo específico de animales considerados mascotas y la sensibilidad que despiertan en las personas, norma que no se extiende a los demás animales explotados por el comercio peletero, como lo son los animales salvajes.

Aunque como veremos, distintos países de Europa han establecido la prohibición del establecimiento de nuevas instalaciones peleteras o bien han fijado plazos para el cierre definitivo de estas granjas, lo cierto es que según cifras del 2018 de la International Fur Federation, en Europa existen 4.350 granjas registradas 
las cuales produjeron 37,7 millones de pieles durante ese año, lo que es una cifra menor a los 42 millones del año 2016. En términos de exportación de productos de piel finalizados la cifra alcanzó los 761 millones de euros $^{24}$.

El panorama actual en la zona europea es diverso, aun cuando la tendencia global sigue marcada por la prohibición ${ }^{25}$. Mientras existen países como Alemania, Reino Unido, Croacia, Suiza y Austria que han establecido normas que prohíben la creación y apertura de nuevas granjas peleteras -manteniendo las que al día de hoy producen pieles animales-, en Dinamarca, país que concentra un tercio de todas las granjas de pieles europeas con cerca de 1.500 establecimientos, ha normado el cierre de las granjas de zorros para el 2023, dejando abiertas las granjas de visones (al menos hasta ahora), y Noruega pretende eliminar todas las instalaciones de explotación peletera para el año 2025. Finalmente, como ya lo vimos a propósito de la emergencia sanitaria del coronavirus y sus consecuencias, en Holanda ya se decidió el cierre de las granjas peleteras para marzo del 2021 y ya no para el año 2024.

En el caso particular de España, existe la Ley 32/2007, del 7 de noviembre de 2007, denominada para el cuidado de los animales, en su explotación, transporte, experimentación y sacrificio. Aunque esta ley general de bienestar animal puede aplicarse a los animales usados para el comercio de pieles (en específico sus artículos 4 y 6), lo cierto es que se trata de una ley diseñada principalmente para cumplir con los requerimientos de la implementación a nivel local de las diversas legislaciones de la Unión Europea sobre bienestar animal. Por ello, esta ley no establece ningún tema en específico para con los animales usados en la industria peletera.

En cuanto a las cifras generales de España, se estima que el número de empresas de al menos 20 empleados que se dedican a la confección peletera ha disminuido de 290 (2009) a 146 (2018). En cuanto a las ventas internas, estas también han caído de 8,8 millones de euros (2009) a 4,1 millones de euros. Mientras que las exportaciones de pieles superan los 15 millones de euros ${ }^{26}$. Respecto de la industria específica de pieles de visón, según cifras de la International Fur Federation (IFF), al año 2018 España contabilizaba 50 granjas peleteras -4 menos que en el año 2016-, concentrando el $80 \%$ de estas instalaciones en Galicia; mientras que ese mismo año se produjeron 750.000 pieles de visón. En el 2020, existen 37 establecimientos peleteros: 31 en Galicia, 1 en Aragón, 1 en el País Vasco, 3 en Castilla y León y 1 en Valencia ${ }^{27}$.

A propósito de esta última información, las autoridades españolas ordenaron en el mes de julio del 2020 el sacrificio de casi 100.000 visones de una granja peletera ubicada al noreste de España, luego que se comprobará que al menos el $87 \%$ de estos animales estaban contagiados con coronavirus y 8 personas que trabajaban en el lugar dieran positivo Covid-19 ${ }^{28}$. Siguiendo el sacrificio masivo en Holanda y Dinamarca, el objetivo sanitario era evitar la propagación del contagio hacia seres humanos y otros animales. Cabe mencionar que, al igual que en estos países, también se comenzó a pedir el cierre de las granjas de visones americanos ${ }^{29}$ por parte de organizaciones internacionales y políticos de España, por el riesgo inminente para la salud de las personas y la biodiversidad ${ }^{30}$. Sin embargo, esta idea no ha prosperado en el territorio español, específicamente en Galicia ${ }^{31}$.

\section{Gasto público asociado al coronavirus}

Como si las cuestiones éticas no fuesen suficientes a la hora de tomar decisiones urgentes, asociadas a los derechos y el sufrimiento de estos millones de animales que están siendo sacrificados a causa del coronavirus, y las cuestiones medioambientales de la industria peletera y las sanitarias relativas al riesgo de

\footnotetext{
${ }^{24}$ El País. Página web: https://elpais.com/sociedad/2019/10/16/actualidad/1571240325_897550.html [Última fecha de consulta: 19 de agosto de 2020]

${ }^{25}$ The Guardian. Página web: https://www.theguardian.com/world/2019/oct/13/fur-ban-california-outlaws-making-and-selling-newproducts [Última fecha de consulta: 18 de agosto de 2020]

${ }^{26} \mathrm{ABC}$. Página web: https://www.abc.es/sociedad/abci-animalismo-y-crisis-cercan-negocio-pieles-espana202001120211_noticia.html?ref=https:\%2F\%2Fwww.google.com\%2F [Última fecha de consulta: 19 de octubre de 2020]

${ }^{27}$ El País. Página web: https://elpais.com/sociedad/2020-07-16/en-espana-se-crian-750000-visones-en-37-granjas.html [Última fecha de consulta: 18 de octubre de 2020]

${ }^{28}$ BBC. Página web:

https://www.bbc.com/mundo/noticias-

53453707\#: :text=Derechos\%20de\%20autor\%20de\%20la,informaron\%20las\%20autoridades\%20de\%20salud [Última fecha de consulta: 18 de agosto de 2020]

29 La Vanguardia. Página web: https://www.lavanguardia.com/vida/20200622/481906562040/unidas-podemos-pide-el-cierreurgente-de-las-granjas-de-visones-americanos.html [Última fecha de consulta: 19 de agosto de 2020]

${ }^{30} \mathrm{La}$ Vanguardia. Página web: https://www.lavanguardia.com/natural/20200616/481816578717/campana-cierre-granjas-visoneswwf-contagios-coronavirus.html [Última fecha de consulta: 15 de agosto de 2020]

${ }^{31}$ Uppers. Página web: https://www.uppers.es/ciencia-y-tecnologia/medio-ambiente-y-sostenibilidad/cierre-granjas-visonescoronavirus_18_3015870226.html [Última fecha de consulta: 15 de noviembre de 2020]

194 Derecho Animal. Forum of Animal Law Studies, vol. 11/4
} 
contagio de enfermedades infeccionas desde animales no humanos a seres humanos, a propósito del gasto que puede significar en términos de compensaciones por el cierre anticipado de las granjas peleteras, cabe tener presente los gastos públicos asociados a la actual pandemia global y la paralización económica.

Mientras que en Chile, como vimos un país sin información sobre posibles contagios en sus granjas peleteras, el gasto asociado a la emergencia sanitaria entre enero y abril del 2020 representa un $0,11 \%$ del Producto Interno Bruto (PIB) -equivalente a \$216.492 millones de pesos ${ }^{32}$. En España se prevé que el déficit fiscal alcance el 10,3\% del PIB durante este año -equivalente a 115.671 millones de euros ${ }^{33}$ - y que el gasto público asociado a medidas de reforzamiento del sistema de salud, protección social y empresarial llegue hasta el 51,5\% del PIB, equivalente a 576.714 millones de euros ${ }^{34}$.

En cuanto a la Unión Europea, cabe destacar que en julio de 2020 se aprobó un plan de recuperación económica 2021-2027 por 1.824 billones de euros ${ }^{35}$, monto que será distribuido en distintos préstamos (360.000 millones de euros que deberán ser devueltos por cada país), subvenciones (390.000 millones de euros reembolsados por los 27 países en bloque) y reformas e inversiones (312.500 millones de euros en subvenciones) $)^{36}$.

A este último punto habría que sumar los gastos propios de cada país, destacando Alemania e Italia con un $34 \%$ de su PIB, seguidos de Japón (20\% de su PIB), Reino Unido (18,8\%), Francia (14,6\%) y Australia $(12,7 \%)$ - todos con inversión mayor a la de España y, por supuesto, Chile ${ }^{37}$.

\section{Propuestas}

La discusión que se está dando en Holanda en cuanto a adelantar el cierre de las granjas peleteras de visones a propósito de las consecuencias del coronavirus, es una discusión que se debe dar en todos los países a nivel global apuntando al cierre definitivo de este tipo de instalaciones. Para llegar a dicha decisión, es necesario identificar los factores de relevancia que surgen a partir de esta situación:

1. La cuestión ética de los derechos animales no humanos utilizados para el comercio de pieles y su sufrimiento, a propósito de no solo las condiciones propias de confinamiento en las granjas peleteras, sino que también cómo las autoridades han decidido el sacrificio de decenas de miles de animales contagiados por coronavirus.

2. La cuestión del impacto medioambiental, a propósito de que la industria de pieles animales genera un mayor impacto negativo en términos medioambientales en cuanto a la suma de indicadores de impacto en comparación con cualquier otra área de la industria textil.

3. La cuestión de seguridad sanitaria, a propósito del riesgo real de contagio de enfermedades infecciosas desde animales no humanos a personas y entre animales, teniendo en cuenta principalmente el caso holandés y el caso danés en que el virus sufrió una mutación en los visones y estos comenzaron a contagiar a personas sanas.

4. La cuestión del gasto público ante la emergencia sanitaria del coronavirus, entendiendo que el gasto es superior a cualquier plan de compensación económica dirigido a los productores de pieles animales ante el cierre obligatorio de sus instalaciones.

Teniendo presente estos factores, y la oportunidad que significa esta crisis sanitaria para evitar que futuras generaciones de animales no humanos sigan siendo explotados y sacrificados por una actividad comercial no esencial, proponemos la implementación de normas específicas -no generales- que determinen la prohibición del comercio de pieles.

En este sentido, sugerimos tomar en cuenta las siguientes medidas según las actuales normas de cada país:

\footnotetext{
${ }^{32}$ CNN Chile. Página web: https://www.cnnchile.com/economia/gasto-publico-pandemia-coronavirus_20200728/ [Última fecha de consulta: 19 de agosto de 2020]

33 La Vanguardia. Página web: https://www.lavanguardia.com/economia/20200730/482584520330/deficit-primer-semestre-2020espana.html [Última fecha de consulta: 18 de agosto de 2020]

34 Economía Digital. Página web: https://www.economiadigital.es/finanzas-y-macro/el-impacto-economico-del-coronavirus-enespana-140-000-millones 20058816 102.html [Última fecha de consulta: 18 de agosto de 2020]

${ }^{35}$ Consejo de la Unión Europea. Página web: https://www.consilium.europa.eu/es/policies/coronavirus/ [Última fecha de consulta: 18 de agosto de 2020]

${ }^{36}$ Emol Chile. Página web: https://www.emol.com/noticias/Economia/2020/07/21/992558/Plan-recuperacion-Union-Europea.html [Última fecha de consulta: 19 de agosto de 2020]

37 Ser. Página web: https://cadenaser.com/ser/2020/04/15/economia/1586952620_404957.html [Última fecha de consulta: 19 de agosto de 2020]
} 
1. Países que no tienen normativa específica sobre comercio de pieles y solo cuentan con normativa general de bienestar animal: se requiere establecer con urgencia una ley específica de carácter prohibitiva, estableciendo plazos distintos para (a) la importación y comercialización de productos que contengan piel animal y (b) la exportación y comercio nacional de piel animal. También se deben eventualmente contemplar plazos distintos de cierres según el tamaño de los establecimientos de producción, así como también se deben contemplar compensaciones únicas ante el cierre definitivo para los dueños y productores. El objetivo es establecer el menor plazo posible ajustado a ejemplos internacionales, teniendo presente también la discusión en Holanda. Es el caso de Chile, por ejemplo.

2. Países que tienen normativa específica y de carácter regulatorio: se requiere modificar con urgencia estas leyes pasándolas de meramente regulatorias a prohibitivas, estableciendo también plazos distintos para la importación, exportación y comercialización de productos derivados de la industria peletera. Eventualmente, se deben contemplar plazos distintos de cierres según el tamaño de los establecimientos de producción, así como también contemplar compensaciones únicas ante el cierre definitivo para los dueños y productores. El objetivo también es establecer el menor plazo posible para este cambio. Es el caso de España, por ejemplo.

3. Países que tienen normativa específica y de carácter prohibitivo: se requiere reformular los plazos previamente establecidos y reducirlos al mínimo más cercano, teniendo presente los cuatro factores revisados y que se asegure un periodo de cierre eficiente y definitivo. Eventualmente, se deben contemplar plazos distintos de cierres según el tamaño de los establecimientos de producción, así como también contemplar compensaciones únicas ante el cierre definitivo para los dueños y productores. Es el caso de países como Noruega y Holanda.

\section{Conclusión}

La tragedia y el horror que significa hoy la pandemia del coronavirus para cientos de miles de animales no humanos, incluyendo no sólo aquellos que son explotados en la industria peletera, sino también aquellos sacrificados en la industria de la alimentación en base a productos de origen animal, es al mismo tiempo una oportunidad sin precedentes para establecer las bases del fin del comercio de pieles animales.

Siendo un área de la moda no esencial, y teniendo presente que la tendencia actual, y ya desde hace años, es fur free, pareciera ser más que conveniente levantar las voces nuevamente y darle el golpe de gracia a esta cruel industria. Más aún cuando al factor del trato ético hacia estos animales no humanos y su sufrimiento, se suman, por una parte, el factor sanitario y el riesgo real de contagio de enfermedades infeccionas para los seres humanos, por otra, las consecuencias negativas en términos medioambientales, y finalmente el factor del gasto público para hacerle frente a la pandemia mundial respecto al gasto que implicaría cerrar e indemnizar a esta industria para asegurar su fin.

En definitiva, nos enfrentamos a un nuevo escenario en donde están dadas todas las condiciones para lograr lo propuesto. Y de ello son claros los ejemplos de las reacciones tanto de organizaciones internacionales como de las propias autoridades que en Holanda, Dinamarca y España alzan la voz para discutir el cierre de esta industria -o adelantar su cierre, en el caso específico de Holanda. Es claro, además, que de lograrse dar este paso en estos países, es muy probable que el mismo resultado, en un especie de efecto domino, llegue a los demás países de la zona y, por qué no, también concluya con una normativa a nivel europeo.

Por supuesto, este posible impacto también debe ser aprovechado por países como Chile y el resto de Latinoamérica que, aunque no nos enfrentamos a una situación tan compleja como la que enfrentan los países europeos, sin duda alguna debemos de actuar con estrategia e inteligencia por los animales y aprovechar las condiciones dadas para exigir normas y resultados idénticos siguiendo el ejemplo internacional.

\section{Referencias}

- ABC. Página web: https://www.abc.es/sociedad/abci-parlamento-holandes-pide-cerrar-granjasvison-este-tras-contagios-coronavirus-

202006240139_noticia.html?ref=https:\%2F\%2Fwww.google.com\%2F [Última fecha de consulta: 15 de agosto de 2020]

- ABC. Página web: https://www.abc.es/sociedad/abci-animalismo-y-crisis-cercan-negocio-pielesespana-202001120211_noticia.html?ref=https:\%2F\%2Fwww.google.com\%2F [Última fecha de consulta: 19 de octubre de 2020]

- Avianca. Página web: https://www.aviancaenrevista.com/revista/especial-moda-las-cifras-de-laindustria-textil/ [Última fecha de consulta: 13 de agosto de 2020] 
- BBC. Página web: https://www.bbc.com/mundo/noticias-52181584 [Última fecha de consulta: 13 de agosto de 2020]

- BBC. Página web: https://www.bbc.com/mundo/noticias-

53453707\#: :text=Derechos\%20de\%20autor\%20de\%201a,informaron\%201as\%20autoridades\%20 de\%20salud [Última fecha de consulta: 18 de agosto de 2020]

- CNN Chile. Página web: https://www.cnnchile.com/mundo/holanda-sacrificar-visones-covid19_20200706/ [Última fecha de consulta: 14 de agosto de 2020]

- CNN Chile. Página web: https://www.cnnchile.com/economia/gasto-publico-pandemiacoronavirus_20200728/ [Última fecha de consulta: 19 de agosto de 2020]

- Consejo de la Unión Europea. Página web:

https://www.consilium.europa.eu/es/policies/coronavirus/ [Última fecha de consulta: 18 de agosto de 2020]

- BIJLEVELD, M., KORTELAND, M., SEVENSTER, M., The environmental impact of mink fur production (Países Bajos, 2011) 6-7.

- DW. Página web: https://www.dw.com/es/dinamarca-defiende-sacrifico-de-millones-de-visones/a55525617 [Última fecha de consulta: 15 de noviembre de 2020]

- Economía Digital. Página web: https://www.economiadigital.es/finanzas-y-macro/el-impactoeconomico-del-coronavirus-en-espana-140-000-millones_20058816_102.html [Última fecha de consulta: 18 de agosto de 2020]

- El Mundo. Página web: https://www.elmundo.es/economia/2020/08/28/5f48c914fdddff78928b45bf.html [Última fecha de consulta: 15 de noviembre de 2020]

- El País. Página web: https://elpais.com/sociedad/2020-07-16/en-espana-se-crian-750000-visonesen-37-granjas.html [Última fecha de consulta: 18 de octubre de 2020]

- El País. Página web: https://elpais.com/sociedad/2019/10/16/actualidad/1571240325_897550.html [Última fecha de consulta: 19 de agosto de 2020]

- Emol Chile. Página web: https://www.emol.com/noticias/Economia/2020/07/21/992558/Planrecuperacion-Union-Europea.html [Última fecha de consulta: 19 de agosto de 2020]

- Evening Standard. Página web: https:/www.standard.co.uk/fashion/luxury-brands-are-ditchinganimal-fur-gucci-michael-kors-maison-margiela-versace-a3805921.html [Última fecha de consulta: 13 de agosto de 2020]

- Fur Free Retailer. Página web: https://furfreeretailer.com/ [Última fecha de consulta: 13 de agosto de 2020]

- HORTA, O. Un paso adelante en defensa de los animales (Madrid 2017) 93.

- Igualdad Animal. Página web: https://igualdadanimal.org/noticia/2012/12/18/holanda-prohibefinalmente-las-granjas-de-visones/ [Última fecha de consulta: 18 de agosto de 2020]

- Independent. Página web: https://www.independent.co.uk/news/world/asia/coronavirus-fur-farmchina-mink-raccoon-fox-wild-animal-a9506976.html [Última fecha de consulta: 14 de agosto de 2020]

- Independent. Página web: https://www.independent.co.uk/environment/coronavirus-fur-trademink-farms-netherlands-a9500061.html [Última fecha de consulta: 15 de agosto de 2020]

- Infobae. Página web: https://www.infobae.com/salud/ciencia/2020/11/14/la-mutacion-de-covid-19procedente-de-visones-seria-mas-mortal-y-podria-alterar-el-desarrollo-de-las-vacunas-en-proceso/ [Última fecha de consulta: 15 de noviembre de 2020]

- Just-Style. Página web: https://www.just-style.com/news/jean-paul-gaultier-to-go-furfree_id134992.aspx [Última fecha de consulta: 13 de agosto de 2020]

- La Tercera. Página web: https://www.latercera.com/que-pasa/noticia/estudios-los-confirmanperros-y-gatos-pueden-contagiarse-de-coronavirus-pero-no-tienes-de-que-

preocuparte/R37YQWXLBRG3HHBRSMQPSHISIY/ [Última fecha de consulta: 13 de agosto de 2020]

- La Vanguardia. Página web: https://www.lavanguardia.com/de-moda/moda/20180110/434198166438/michael-kors-jimmychoo-pieles-animales-iniciativa-peta-gucci.html [Última fecha de consulta: 13 de agosto de 2020]

- La Vanguardia. Página web: https://www.lavanguardia.com/natural/20200525/481386452450/holanda-coronavirus-visonescontagio-humanos.html [Última fecha de consulta: 14 de agosto de 2020] 
- La Vanguardia. Página web: https://www.lavanguardia.com/natural/20200616/481816578717/campana-cierre-granjas-visoneswwf-contagios-coronavirus.html [Última fecha de consulta: 15 de agosto de 2020]

- La Vanguardia. Página web: https://www.lavanguardia.com/economia/20200730/482584520330/deficit-primer-semestre-2020espana.html [Última fecha de consulta: 18 de agosto de 2020]

- La Vanguardia. Página web: https://www.lavanguardia.com/vida/20200622/481906562040/unidaspodemos-pide-el-cierre-urgente-de-las-granjas-de-visones-americanos.html [Última fecha de consulta: 19 de agosto de 2020]

- NIMON, J. Y BROOM, M., The welfare of farmed mink (Mustela vison) in relation to housing and management: a review, en Animal Welfare, 8 (1999) 209.

- People. Página web: https://people.com/style/fur-free-luxury-fashion-brands/ [Última fecha de consulta: 13 de agosto de 2020]

- Real Academia Española. Página web: https://dle.rae.es/moda [Última fecha de consulta: 31 de agosto de 2020]

- Science. Página web: https://www.sciencemag.org/news/2020/06/coronavirus-rips-through-dutchmink-farms-triggering-culls-prevent-human-infections [Última fecha de consulta: 14 de agosto de 2020]

- Ser. Página web: https://cadenaser.com/ser/2020/04/15/economia/1586952620_404957.html [Última fecha de consulta: 19 de agosto de 2020]

- The Guardian. Página web: https://www.theguardian.com/world/2019/oct/13/fur-ban-californiaoutlaws-making-and-selling-new-products [Última fecha de consulta: 18 de agosto de 2020]

- Uppers. Página web: https://www.uppers.es/ciencia-y-tecnologia/medio-ambiente-ysostenibilidad/cierre-granjas-visones-coronavirus_18_3015870226.html [Última fecha de consulta: 15 de noviembre de 2020]

- W Magazine. Página web: https://www.wmagazine.com/story/kim-kardashian-faux-fur-coats/ [Última fecha de consulta: 13 de agosto de 2020] 